\title{
The purpose and impact of postgraduate knowledge
}

\author{
Gina Wisker CLT, University of Brighton, Brighton, UK \\ Gillian Diana Robinson, Anglia Ruskin University, Chelmsford, UK, and \\ Brenda Leibowitz, University of Johannesburg, Johannesburg, South Africa
}

\begin{abstract}
Purpose - Much research into outcomes of doctoral learning focuses on employability, or the dearth of academic employment in relation to doctoral graduate expectations, emphasising precarity of academic future work. This new work begins with and moves beyond employment issues, highlighting professional practice and personal knowledge development and impact.
\end{abstract}

Design/methodology/approach - Much doctoral education research focuses on the academic identities of postgraduates, their change and alignment to the work and experience of being a doctoral student and beyond, in academic or other jobs. This longitudinal work explores professional and social impact from doctoral research and transformational changes experienced and reported by graduates in two projects. Based on narrative interviewing turned into case studies, it asks fundamental questions about the purpose and impact of postgraduate knowledge.

Findings - Respondents emphasised change in their sense of personal, academic and professional identity; immediate impact on professional practice leading to job change, status, changes in practices and longer-term impacts of further influences on professional practice, some international in reach.

Research limitations/implications - This small-scale study has widespread implications for understanding the impact of postgraduate knowledge on professional practice and personal development.

Practical implications - The work could influence doctoral student intentions and the focus of doctoral programmes.

Social implications - Postgraduate knowledge is seen as crucial in theorised and practical contributions to social development.

Originality/value - This longitudinal work generates new knowledge, answering questions: What is the purpose of postgraduate knowledge? Who benefits from results? What is the impact from the research? How are outcomes put into professional practice? It found significant developments in professional practice and personal development.

Keywords Identity development, Doctoral learning, Postgraduate knowledge, 


\section{Introduction}

University websites and promotional materials for doctoral study tend to emphasise the broad benefits of completing a doctorate, while some mention as learning outcomes the skills acquired. While international publications on the impact of the PhD tend to focus on movement into or lack of academic jobs, university information sources identify learning outcomes in terms of skills developed through undertaking and completing a PhD, even where a potential social justice or change outcome is intended. Some also mention personal development. For example, the University of Cambridge Wellcome Trust 4 Year PhD Programme in Infection, Immunity and Inflammation includes in its PhD learning outcomes developing research skills and:

- having self-direction and originality in tackling and solving problems; and

- being able to act autonomously in the planning and implementation of research.

These are skills outcomes for the doctoral graduate rather than identity changes or outcomes of effects and impact of their research. The University of Bergen outlines skills and both research-specific and general competency learning outcomes that:

can identify, analyse and critically reflect on research ethics as these relate to research projects and areas; can conduct research and dissemination with academic integrity and in accordance with the basic values of academic activities; can account for and critically reflect on conflicts of values and interests in their own research area and in the relationship between their own research area and other social actors; can contribute to the management of, and can collaborate on, complex interdisciplinary tasks and projects; can disseminate research and development through highly ranked national and international channels; can participate in debates within their subject area in national and international forums; and can evaluate the need for renewal, and can initiate and engage in ground-breaking thinking and innovation (Norwegian Agency for Quality Assurance).

The last of these seems to suggest broader behavioural change although directed at Norwegian research contexts. Other sites emphasise teaching as an outcome. Focusing on the value of the discipline, WA State University states:

- Demonstrate, through service, the value of their discipline to the academy and community at large (service, content, knowledge).

- Demonstrate a mastery of skills and knowledge at a level required for college and university undergraduate teaching in their discipline and assessment of student learning.

In the 2012 report "What Do Researchers Want to Do?" the UK-based researcher organisation Vitae indicated that around one-third of the then 4,500 postgraduate researchers "had definite ideas about their future careers, and about a fifth had little or no idea". In 2013 statistics, they provide visual representations of job outcomes by discipline area, noting in the UK: "82 per cent of doctoral graduates in 2010 believed that their skills and competencies were a formal requirement or important in gaining current employment; similar to master's (84 per cent) and good first degree respondents (86 per cent)". They have a useful set of thought-provoking questions to focus graduates on employability, next steps 
$\mathrm{O} 2$ and the precarity of an academic future, sharing career stories and advising the following:

- Consider your next move as early as possible. How you spend your time during your doctorate will have an impact on your future career.

- Doing your doctorate may be part of a clear career strategy, an attempt to change direction or simply an interesting opportunity. Continuing in academia is no longer a certainty, neither is it necessarily the most desirable option after a doctorate. Even if you are clear about what you want to do, you can still think about how to achieve your aims and consider alternatives in case plan $A$ is not successful.

- Gaining useful skills and experience can enhance your employability. You may also find opportunities to explore possible career paths through work placements. Teaching or demonstrating during your doctorate is one example and your institution might have links to employers or even a placement scheme.

- If you have not yet made up your mind, you are not alone. (Vitae, 2018)

\section{Context and literature}

Issues of undertaking a professional practice-based doctorate, or a doctorate which intends to feed into change in practice, and then of the usefulness (or not) of doing a doctorate all emerge in the literature. Some issues concern identity, position and of potential future job prospects which all emerge as of importance. A major issue of undertaking a doctorate related to professional practice emerges from the literature as the sudden surprising engagement with theory (which is felt as alien) so one of Margaret Kiley's respondents notes that “Theory was another thing I didn't understand, people kept asking me about my theoretical perspective but I didn't have a clue what they were talking about" (Kiley, 2015, p. 57). Others mention challenges to a sense of professional competence (Adendorff, 2011). For those working in education, (which is pertinent to many of our respondents in both Projects A and Project B), there are issues of identity, (colleague and student) and challenges to credibility in the home department disciplinary community (Hutchings and Shulman, 1999). Less has been written about what graduated doctors actually do in terms of careers and particularly academic careers, changes in professional practice, changes in their own lives.

Australian data suggest the greatest growth in those undertaking PhDs is in the over $60 \mathrm{~s}$ (Kiley, 2015) and, as with other international research, that there is no high correlation with entering academic careers. The dearth of academic jobs is probably one cause, and another, we would argue, is because mid-career professionals take PhDs, and their new knowledge and processes, into making an impact in their established or newer work. In "Doctoral students and a future in academe? From the iceberg to the shore", Acker and Haque (2009) ask "Are doctoral students best thought of as faculty-in-waiting?" Over half of doctoral graduates in Canada are employed outside the academy (McAlpine and Norton, 2006, p. 11). Although not all doctoral students complete, some become immersed in the institutional culture, disciplinary and departmental, learning research practices and thinking (six years in the social sciences) (Gluszynski and Peters, 2005, p. 25). Acker and Haque (2009) consider future academic identity - seeing beyond the doctorate and what are the issues about developing academic identity for future roles?

They found most students expected and prepared for an academic career, producing publications and teaching, seeing it as a struggle and worrying about job prospects after so much hard work. Others speak of the "risk career" of academic employment (Castello et al., 
2015). Writing on professional practice-oriented work, challenges to a sense of professional competence (Adendorff, 2011) are noted, and for practising academics and other professional mid-career researchers, a challenge to their credibility in home department disciplinary communities (Hutchings and Shulman, 1999). In her work on doctoral graduates who move into careers other than in academia, Inger Mewburn in her presentation on researcher employability research at the Quality in Postgraduate Research conference 2018, notes that employers rarely mention a PhD in their job adverts and notes 80 per cent of the jobs identified by the algorithm as suitable for a PhD graduate did not have "PhD" in the text, suggesting low levels of employer awareness of the value of a PhD, heralding the development of a free-to-access learning platform called "Post-Ac": a new kind of search engine for PhD candidates and graduates, while her and colleagues' work (Mewburn et al., 2017; Mewburn et al., 2018) starts to spread the net more widely.

Sarah Ryan (2018), from the University of Wollongong, in a presentation later in 2018, shared a number of websites and developments focused on doctoral graduate employment support and directions, including industry placements, and the HDR Career Conversations Blog 2018. Focusing on professional and academic outcomes but also emphasising effective characteristics which should be developed for postgraduate success within and beyond the $\mathrm{PhD}$, Dr Steve Joy, Cambridge University researcher development, blogs to suggest the important of self-leadership. This he argues enables doctoral students and graduates to take more control of their development and future careers: "self-leadership entails an outwardlooking mindset - being conscious and careful in sharing our ideas and opening up our networks" (Joy, 2014). PhDs are neither enough nor always appropriate for professional futures, and a range of attitudes and skills which can accompany these and develop beyond the PhD could influence versions of success and of impact. Postgraduates are both being directed and striving to look beyond academic careers and to realise a fuller range of their own skills, qualities and mindsets, useful in first and future jobs, and also in selfdevelopment and self-actualisation. It is these latter directions, which relate more to the research we conducted for the most part with early- and mid-career professionals undertaking PhDs, some looking for academic jobs, some already in academic jobs and most seeking enhancement through undertaking the PhD.

\section{Methodology and methods. Our research for project(s) A and project B}

We begin all our research in the (constantly updated) international literature on postgraduates, academic jobs and identities and postgraduate outcomes from undertaking doctorates.

Our work in Project(s) A and Project B takes two approaches to explore those outcomes, focusing on the perceived impact on postgraduate lives and professional practice.

(1) Project(s) A is based in the re-scrutiny of data collected during five earlier research projects (i-v), involving international participants (1998-2013) and colleagues at our own universities: Anglia Ruskin, Brighton and Johannesburg (2007-2018), with an enhanced focus on academic identity, social justice and professional practice outcomes. These earlier projects are:

(i) One which focused on 250 members of a large international cohort-based $\mathrm{PhD}$ programme (1998- 2006) using the reflections on learning inventory (Meyer and Boulton Lewis 1997) to relate research approaches with intended outcomes; (ii) HEA/HEFCE National Teaching Fellowship funded "Doctoral Learning Journeys" (Wisker et al., 20082011) which involved UK and international participants; (iii) the international Sir Ron Cooke scholarship (Wisker, 2011-2013) involving international participants (Australasia, S Africa, 
Sweden); (iv) an internally (University of Brighton) funded project focused on social justice and social justice doctorates (2012-4); (v) a project with Brenda Leibowitz and Pia Lamberti at the Universities of Johannesburg and Brighton (2015-7) focusing on academic colleagues undertaking postgraduate research into their own professional practice gathered data from both the UK and South Africa. The doctoral students in this are academic staff in various disciplines, colleagues completing doctorates and very much focused on professional practice impacts.

The results from the above earlier projects (i)-(v) overall have been shared in a range of publications (see bibliography) and our purpose in returning to them in Projects $A$ was to rescrutinise the data to seek specific information, findings and arguments linking ontology, identity and intellectual knowledge production, for professional practice.

Project B. For this new project focused on moving through the doctorate for transformational outcomes, we undertook new research, and to do so we returned to the research participants with whom we had engaged in the five earlier research projects to focus on their own perceived impact and outcomes from their doctorates. We therefore engaged with an opportunistic sample (our previous participants), of international (Sweden, S Africa, Israel) and UK doctoral graduates all of whom had been focused on PhD research related to their professional practice. These are graduates whose journeys were known to us from the five historical research projects 1998-2018 (Projects A), some of whom were members of the large international PhD programme (last intake 2006) and some of whom were academic staff at the universities of Brighton, Anglia Ruskin and Johannesburg.

We re-scrutinised data collected during the five earlier or contingent research projects of Project(s) (A)(1998-2018) specifically and only considering data and findings concerning academic identity, social justice outcomes and professional practice outcomes. Everything reported below from Projects $A$ focuses in these issues alone.

Our research for Project $B$ involved further exploration of the literature, and reestablishing contact via email, and re-engaging with the participants from the earlier projects (Projects A) to explore their perceptions of effects of postgraduate knowledge. The new research uses semi-structured open-ended interview questioning, face-to-face or by email. Thirty previous participants responded with information concerning their perceptions of the impact of the experience of engaging with their research, its processes, products and outcomes.

For both Projects A and B the data were thematically analysed. For Projects $A$, it is reported in quotations related to these themes and for Project $B$ re-storeyed into narrativebased case studies, derived from data presented directly by the participants. These anonymised case studies showcase emerging themes, examples of professional, personal and social transformations, and for the postgraduates, the impact of the experience of engaging with their research, its processes, products and outcomes.

The research findings offer information on impact enabled by PhD completion in terms of changes in identity, ontology, epistemology and effect on professional working practices.

Findings reported below are from both projects as labelled, because the work in Project(s) A underpins and informs the explorations in Project B. However, most of this article focuses on Project B, re-storeyed case studied as labelled.

The historical research and the rescrutiny of data was ethically approved (Projects A) through the University of Brighton, Anglia Ruskin University and the University of Johannesburg. Project B was ethically approved through Anglia Ruskin University and the 
University of Brighton. All respondents are re-labelled from A to $\mathrm{F}$ and cases are also allocated random alphabetical letters.

\section{Data, discussion and findings}

\section{Projects A Findings}

For this earlier work, we asked and found out about:

- What is complex in the journey?

- What do you struggle with and what do you engage with and gain?

- Engaging with theory.

- Theorising your practice.

- Engaging with methodology and methods.

- Working conceptually.

- Researching and evaluating practice and real world questions.

- Entering a field of scholarship.

Results from Projects A indicated difficulties faced in research related to one's professional practice:

It was a very very lonely hard road $(A)$.

It was extremely overwhelming [...] I didn't realise the extent and the depth of the discourse and the discipline (B).

[...] I didn't even know who Vygotsky was, to give you an idea. I knew absolutely nothing@.

It was quite tricky in the beginning, because I couldn't just write, I didn't have extensive background, so it was quite limiting, or limited, and I think even today it's limited. [...] I will always be a bit on the back foot, I think, because I don't have that, you know, 20 years of experience $[. .$.$] there is just something that comes from having 20$ years of education behind you (Leibowitz et al., 2017)(D).

\section{Project B Moving through the doctorate for transformational outcomes,}

The most recent work (Project B, 2017-18) Current research focuses on the impact of this postgraduate study on professional practice, knowledge creation and personal development. It uses email and face-to-face interviewing with previous participants from the UK, SA, Sweden, Israel using semi-structured open-ended questions. They are all doctoral graduates whose work focuses on their professional practice and has fed into it. These semi-structured narrative interviews have been turned into short narrative case studies.

Our research asks:

- Why do we undertake doctorates?

- What is the purpose of postgraduate knowledge?

- How are results and skills etc. development used and put into professional practice, and what is the impact from the research?

- How does the doctoral research journey engage with and lead to transformation for the postgraduates themselves?

Our research then moves on to explore two forms of impact.

First, it considers the transformation of learning and its effects upon the researcher's identity and sense of self and achievement. We consider the ways in which PhD students gain a 
new sense of achievement and identity as a research journey outcome, and the impact of the experience of engaging with the research, the process and product.

Second, we explore the transformation of learning and the results of research in terms of the impact and effective changes which it achieves. In this, we consider a range of PhDs undertaken by various students internationally, all of which were focused on professional practice. We consider in what ways some of the graduates changed their professional practice as a result of their research.

The research engages with issues and practices, including pathways to impact and articulation of the research, the importance of previous status and contacts, the importance and the difficulties of communication and practices of engagement, for example, publication and presentation.

\section{Project B after the doctorate: Looking at life after}

We considered a range of PhDs undertaken internationally, up to 16 years ago, all focused on professional practice, considering in what ways graduates changed their professional practice as a research result.

Our respondents emphasised change in their sense of personal, academic and professional identity; some immediate impact on professional practice leading to job change, status, changes in practices and longer-term impacts where research outcomes lead to further developments in professional practice, some international in reach. They take the newly theorised, conceptualised, thoroughly explored and extended work into some form of social and/or professional practice change, aware of the usefulness of the levels of understanding, theorising and practice enabled on a research journey and an appetite to enable positive change. They become active, research-informed transformers.

We constructed short case studies from the data to explore identified outcomes focusing on the purpose and impact of postgraduate knowledge for the graduates, and in terms of affecting or changing understanding and practices. For some respondents on the project, a focus in the PhD on social justice and critical professionalism relates to metacognition, awareness of and ownership of learning, informed agency and valuable transferable skills. Research suggests that students experiencing these processes and practices are highly engaged with their learning, underpinning their practices with values and transfer this learning to successful study, employability and an orientation towards the public good. This kind of research work grows from professional practice and feeds into it; it is informed by social justice and critical professionalism and operates strategically and at levels of implementation and experience. Values and vision underpin the range of actions, linking practical application with dedication for transformative purpose. Interesting models emerge ranging from individual projects and practices to access programmes to doctoral schemes and support strategies from the highest levels.

Postdocs have noted:

- personal changes;

- changes in their professional practice; and

- local and widespread change and effectiveness.

\section{Findings and discussion}

For some the results were mainly personal: 
To sum up, my doctoral journey was a personal journey, a soul searching journey. Its effect on my professional life were just secondary gains. (E)

However, others noted career enhancement, gaining: "A huge professional and academic growth". (F)

\section{Extended cases}

Case O. Professionally, she worked with non-demented patients who had Parkinson's disease. She developed strategies to teach people with Parkinson's to re-learn how to swallow, using video-assisted swallowing therapy. The treatment is now extended to patients with Huntingdon's and operates in a number of countries.

Of the effects on her professional practice, she noted:

Since my PhD I was easily promoted in the hospital and college that I'm working, I'm more involved in mentoring and education. No doubt that the 'PhD' or 'Dr.' assisted in the growth of my private practice. Research became a major part of my job.

I feel more appreciated by people from my profession and more collaborations with other researches.

Of the effects of completing the PhD on herself, her identity, she said: "It affected only my professional life".

Case N. An educator of children with disabilities, in particular cerebral palsy, $\mathrm{N}$ discovered a link between the physical and the social, building a chair which brought the children slowly out of water. While beginning to develop confidence in both their motor and social skills, water immersion gave them bodily control and enabled them to relax and show more signs of social engagement. About his professional practice development he notes success, esteem and recognition: "The research affect my professional practice by change my paradigm of thinking about phenomenon in our world".

Cases in reality are always more complex than invented ones. He also had severe dyslexia which he perceived as a lifelong disability to be managed with control, planning and calm.

Moreover, during the research learning journey, his supervisors both left the university, so he also had a setback and had to engage with explaining it in detail to another new supervisor, an educator without the engineering or disability background. Parts of this breakthrough in understanding which he created, constructed and found in his ongoing research, and part of the confidence to articulate this in the PhD viva began in having to explain it all utterly clearly to the new supervisor. This provided an accidental learning opportunity and a breakthrough in his understanding. Many of his responses integrate the professional and the personal impact of his research work:

The PhD research affect me by prove for myself that I have the ability, talent, knowledge motivation and competence to do such a great journey-research that before the research I did not think I had the abilities and the guts to do.

In the school that I teach the people around me is thinking that $\mathrm{N}$ is the person to talk about research and methodology.

It's able to 'blast out' all the qualities, abilities and my capabilities that I have to challenge myself to the most and to succeed. The research affect my identity by give me personal confident, improve my motivation to succeed in other fields and subjects. $(\mathrm{N})$

It also enhanced his sense of self-esteem and confidence. 
Case M. Another respondent is a practising somatic therapist concerned with trauma, for whom the PhD was not only an enhancement of status and a legitimation of the professional practice in which she was engaged but also a stretching and developing of and a confirmation of her abilities as a professional practitioner and a researcher. Her title "'Rejoining the Stream of Life' - An Integrated Model of Trauma Group Therapy Combining Dance-Movement Therapy and Somatic Experiencing for Elder Women Suffering from Spouse Abuse" emphasises research and professional practice-based change for participants in both their behaviour and their sense of confidence. The doctoral graduate enhanced her own professional practice and this was directly related to her own self, of confidence, selffulfilment, change in others' lives by helping them change their perspectives and behaviours and extending this internationally through both therapy and writing. Eliding the personal and professional, she notes:

The emotional effect of the PhD quest in my professional life is wide. I feel more confident, I have more internal belief in myself.

I am more courageous to say, write, present my contributions to various audiences, go to new, and sometime far places in the world to bring myself and my knowledge.

In life, I am taking ideas, test in practice in various levels (from just gathering testimonials from participants, to systematic research) and transfer it or generalise it to various populations, purposes, implications.

A new gift I got is that of a higher ability to conceptualise, and to invent new concepts.

Of her professional practice, she notes not just further successes and international reputation but specific transferable skills:

- the academic ability with the personal ability to lecture and present in front of people, or an audience;

- "I am able to write presentation, working materials and papers or chapters and publish - in Hebrew - my mother tongue, and English as well";

- the direct result of my PhD was developing the STREAM* model; and

- I was invited to be a co-director in an NGO: Connections and Links from Trauma to Resilience.

Case T. For this student, learning was the main motivation for doing a master's and then a $\mathrm{PhD}$. She said "I saw and still see myself a lifelong learner".

The focus of the PhD was on behaviour problems in the early years and management approaches used by pre-school teachers.

The topic was chosen mainly because of two professional challenges: a) children who were excluded from mainstream school and referred to the special school mainly because teachers did not have (or were not prepared) to deal with children's behaviour; (b) children who were withdrawn/timid who presented a bigger challenge.

Developments related to herself include both confidence and also caution, which leads to research before decision-making:

To start with, I didn't think that doing a doctoral study changed me or my identity as an individual or professional. Now thinking about it, I can see how doing a doctoral study has changed my perception of myself as being a doer and completer of any challenge, selfinflicted and/or imposed, and my attitude towards life and others being less certain and judgmental. 
Of her professional practice, she notes that: "Professional practice became constantly questioning, evidence and argument".

In addition:

Making an academic (and intellectual?) leap from the world previously shared with them can be a lonely and alienating experience, as assumed shared valued and beliefs may not be shared anymore. This can also bring conflict of opinion and world views, requiring a constant fine balancing act in discussions and debates, so that I remain true to my own values, beliefs and arguments and at the same time I contribute to these discussions maintaining the selfrespect and dignity of my co-discussants. Often trying to open up and widen the arguments, especially for issues of any sort of diversity and inclusion can become really trying [...].

To sum up, my doctoral journey was a personal journey, a soul searching journey. Its effect on my professional life were just secondary gains.

\section{Personal and community}

\section{Case $Y$}

One respondent was highly enthusiastic about the effects on his all-round life and noted:

The close society - family and colleagues - appreciate this, including my students, who are proud of their lecturer who is perceived as a role model. A role model in the practical area and in the cognitive area - doctor and a professional. Usually, when I publish or when I participate in conferences, professional development courses or workshops then the title is meaningful.

My students too - they appreciate me and they were my catalyst for my research. I dedicated this research to my students while other people usually dedicate their PhD to their family. (Y)

\section{Moreover:}

My wife fell in love with me more, she appreciates me more, especially my father-in-law. (Y)

\section{Implications}

Both Projects A and Project B, on which this article is mainly based, focused on the impact and effects of postgraduate knowledge, finding such impacts and changes took place in professional practice and in personal achievement, including elements such as a confident practice based on confident research. It causes us to consider the importance, the impact and the wide-ranging effects of undertaking and completing a doctorate, which move beyond the kinds of skill development and graduate attributes embedded in university marketing and learning outcome statements. Our work was able to determine these changes partly because the combinations of Projects $A$ and $B$ comprise a longitudinal study (of participants in projects over many years, re-contacted to explore the outcomes and impacts of their doctoral experience and work and our contact in 2017 and 2018. Although longitudinal study is relatively unusual in doctoral research, we would argue that it is necessary for capturing impact, both professional and personal, by following up on professional contact with the earlier participants.

Our research produced some comments from the respondents, which suggest ways of transferring from the research process to practice, and wider effectiveness. Generally, these include issues and practice around issues from the process and the journey as much as the focus of the work; questions about how a doctorate aimed at changes in professional 
practice can be structured and effectively carried out; the characteristics of reported breakthroughs and developments resulting from the focus of the work. Other issues focused on how a postgraduate can gain entry to contexts to effectively transmit knowledge and effect change; the importance of initially working with stakeholders and developing the contacts during and after the $\mathrm{PhD}$, marketing and communications including placing reports of the work in a wide variety of contexts - academic papers, blogs, trade papers, community locations to engage interest and effect change; using the leverage of existing roles and contacts to persuade others to take up the outcomes and changes suggested by the work in practice, so it can be taken into professional practice.

Insider knowledge, position, local politics and contacts are considered important in taking the outcomes of the work further into practice. We ask and (at least in some part) answer the question: what is the nature of $\mathrm{PhD}$ doctoral knowledge its outcomes and impact? It's all about:

- Transformation. Personal development and academic and professional identity are engaged with this.

- Problematising given ways of working and experiencing, questioning practices and their underpinning values, using insider knowledge to ask questions, develop and change.

- Enhancing a practice position with theorising, conceptualising, rigorous researching (methodology and methods, etc.).

How is this done? Participants indicated that this can be done through putting their practical, practitioner knowledge construction and conceptual understanding, meaning, contribution, into practice, in context.

Making breakthroughs in learning supports the recognition of the achievement in the doctorate, which can then be explored to share the development with others.

From this research, we are aware that there is little use in postgraduate research if it does not make a change in:

- values;

- behaviours;

- understanding;

- knowledge construction;

- practices;

- the field; and

- $\quad$ and the self. To do so, it has to be shared and rolled out, like publications. It is up to us to market and connect and share.

\section{Conclusions}

Our research explores and highlights two forms of impact. It offers new knowledge concerning the purpose and effects of postgraduate knowledge in terms (i) of theOur research explores and highlights two forms of impact. It offers new knowledge concerning the purpose and effects of postgraduate knowledge in terms (i) of the impact on the individual's sense of identity, self-worth, awareness for growth in construction and creation of knowledge, and (ii) realisation of, and evidence for, the impact of their research and intellectual skills developed during the $\mathrm{PhD}$ and the project itself, which has led to (iii) changes in professional practice often with both a local and an international impact. This involves construction and querying of established learning, knowledge and ways of carrying 
out a range of activities and behaviours, all of which have been influenced (respondents report) by the experience of successfully undertaking a PhD.

\section{References}

Acker, S. and Haque, E. (2009), "Doctoral students and a future in academe? From the iceberg to the shore", Canadian Society for the Study of Higher Education Conference, May, pp. 25-27.

Adendorff, H. (2011), "Strangers in a strange land: on becoming scholars of teaching", London Review of Education, Vol. 9 No. 3, pp. 305-315.

Castello, M., Kobayaski, S., McGinn, M., Pechar, H., Vekkaila, J. and Wisker, G. (2015), "Researcher identity in transition: signals to identify and manage spheres of activity in a riskcareer", Frontline Learning Research, Vol. 3 No. 3, pp. 35-50, doi: 10.14786/fIr.v3i3.149.

Gluszynski, T. and Peters, V. (2005), "Survey of earned doctorates: a profile of doctoral degree recipients", the Association of Canadian Academic Healthcare Organization, p. 25, available at: www.acaho.org/docs/pdf phds health research.pdf

Hutchings, P. and Shulman, L. (1999), "The scholarship of teaching: new elaborations, new observations", Change, Vol. 31 No. 5, pp. 11-15. Joy, S. (2014), "Self-leadership: the game of higher education and how best to play it", available at:

http://earlycareerblog.blogspot.com/2014/06/self-leadership-game-of-higher.html (accessed 15 September 2018).

Kiley, M. (2015), “I didn't have a clue what they were talking about': PhD candidates and theory", Innovations in Education and Teaching International (Special Edition on Doctoral Education), Vol. 52 No. 1, pp. 52-63 (57).

Kiley, M. (2015), "Troublesome knowledge and the professional, mature-age PhD candidate", paper presented at EARLI conference, Limassol, available at: www.ee.ucl.ac.uk/mflanaga/abstracts/ TC14Abstract10.pdf

Leibowitz, B., Wisker, G. and Lamberti, P. (2017), "Postgraduate study in uncharted territory: a comparative study", in Fourie-Malherbe, M., Albertyn, R., Aitchison, C. and Bitzer, E. (Eds), Postgraduate Supervision - Future Foci for the Knowledge Society, SUN MeDIA, Stellenbosch.

Leibowitz, B., Wisker, G. and Lamberti, P. (2018), “'Crossing over' into research on teaching and learning", in Bitzer, E. (Ed.), Spaces, Journeys and Horizons for Postgraduate Supervision, SUN MeDIA, Stellenbosch.

McAlpine, L. and Norton, J. (2006), "Reframing our approach to doctoral programs: an integrative framework for action and research", Higher Education Research and Development, Vol. 25 No. 1, p. 317, doi: 10.1080/07294360500453012. 
Mewburn, I. Suominen, H. and Grant, G. (2017), "Tracking trends in industry: demand for Australia's advanced research workforce", Australian National University, available at: http://cpas.anu.edu.au/files/Mewburn,\%20Suominen\%20and\%20Grant\%202017\%20Trackin g\%

20Trends\%20in\%20Industry\%20Demand\%20for\%20Australia's\%20Advanced\%20Research \%20 Workforce.pdf

Mewburn, I., Pitt, R., Grant, G. and Suominen, H. (2018), "Desperately seeking MacGyver: doctoral employability as read in non-academic job adverts asking for advanced research skills (a machine learning study)", Quality in Postgraduate Research conference, Adelaide.

Sarah Ryan, S. (2018), "Career ready research students: an Australian perspective", May 2018, available at:

www.ahecs.ie/resources?keys=sarahpryan\&field_subject_area_target_id=All\& field_resource_type_target_id=All

Vitae (2018), "After your doctorate", available at: www.vitae.ac.uk/researcher-careers/afteryourdoctorate (accesesd 11 April 2018).

\section{Further reading}

Norwegian Agency for Quality Assurance (2019), "Norwegian agency for quality assurance in education (NOKUT), Tilsynsforskriften 4.2", University of Bergen, available at: www.uib.no/en/ phd/74883/learning-outcomes

University of Cambridge (2019), "Wellcome trust 4 year PhD programme in infection, immunity and inflammation, school of clinical medicine", Cambridge Institute for Medical Research, Department of Veterinary Medicine, Department of Pathology, available at: www.cimr.cam.ac. uk/documents/phd-aims-iii-programme

Vitae (2012), "What do researchers want to do?", available at: www.vitae.ac.uk/vitaepublications/ reports/wdrwtd-the-career-intentions-of-doctoral-graduates-feb12.pdf

Washington State University (2019), "Examples of student learning outcomes for PhD programs", available at: https://gradschool.wsu.edu/student-learning-outcomes-ph-d/

Wisker, G., Morris, C., Cheng, M., Masika, R., Warnes, M., Lilly, J. Trafford, V. and Robinson, G. (2010), "Doctoral learning journeys - final report of the NTFS-funded project", available at: www.

heacademy.ac.uk/resources/detail/ntfs/projects/doctoral_learning_journeys

Corresponding author Gina Wisker can be contacted at: ginwskr@aol.com 